\title{
Emission of Fine Particles and Ageing Behavior of PTFE Finished Filter Media during Industrial Pollution Control
}

\author{
Arunangshu Mukhopadhyay ${ }^{1} \&$ Harshad S. Bawane ${ }^{1}$ \\ ${ }^{1}$ Department of Textile Technology, National Institute of Technology, Jalandhar, India \\ Correspondence: Arunangshu Mukhopadhyay, Department of Textile Technology, National Institute of \\ Technology, Jalandhar 144011, India. E-mail: arunangshu@nitj.ac.in
}

Received: August 27, $2015 \quad$ Accepted: September 14, 2015 Online Published: September 28, 2015
$\begin{aligned} & \text { doi:10.5539/ep.v4n4p58 } \\ & \text { URL: http://dx.doi.org/10.5539/ep.v4n4p58 }\end{aligned}$

\begin{abstract}
Present study embodies the effect of two different filter media viz. polyester filter fabric treated with PTFE finish and polyester fabric filter without finish, and two different dust concentration $\left(50\right.$ and $\left.150 \mathrm{~g} / \mathrm{m}^{3}\right)$ on industrial pulse-jet filtration process performance. The fabrics were tested based on ISO - 11057 Standard, while conducting 200 pulsing cycles at measuring phase. Emission in terms of mass concentration $\left(\mathrm{PM}_{2.5}, \mathrm{PM}_{10}\right)$ and number particle concentration are substantially lower while using PTFE finished filter media in comparison to media without finish. Outgoing particle number largely reduced while using PTFE treated fabrics particularly at higher dust concentration. The particle size distribution in the downstream side reflects that use of PTFE finish filter is particularly more beneficial for capturing very fine particle. PTFE finish fabric also exhibit lower residual pressure drop as compared to unfinished fabric during measuring phase of filtration operation. Further it was also evident that the trend of residual pressure drop with time is quite stable for PTFE finished fabrics. The said fabric get stable (age) earlier than without finish, hence expected to provide more consistent filtration behaviour for longer time.
\end{abstract}

Keywords: particle size distribution, PTFE finish, pulse jet filtration, residual pressure drop

\section{Introduction}

The environmental issue has become a major subject in the last few decades, affecting science and technology of the entire world due to serious environmental impacts caused by air pollution. Environmental pollution has negative influences on human health, on ecological systems, the greenhouse effect, the ozone layer, etc. Aerosols or airborne particles are present in our environment either by nature or through human activities. They come in many forms such as dust, mist, fume, smoke and fog. Airborne dust particles are rarely homogeneous and vary greatly in size and shape, and their chemical composition is determined by factors specific to the source and location of emissions. These aerosols also affect visibility, climate besides human health and quality of life (Yang, 2012; p. 1). Effective means of preventing and controlling air pollution is therefore utmost important. In industrial gaseous pollution control, fabric filters in general provide high collection efficiencies on both coarse and fine (submicron) particulates. They are relatively insensitive to fluctuations in gas stream conditions. Efficiency and pressure drop are relatively unaffected by large changes in inlet dust loadings for continuously cleaned filters. Over past two decades, fabric filter embedded with pulse-jet filtration (Mukhopadhyay, 2009; Mukhopadhyay, 2010) has become the most preferred choice providing sound technical and commercially attractive solutions in controlling industrial pollution.

One of the major thrust of recent development in industrial dust emission is to control very fine particles $\left(\mathrm{PM}_{2.5}\right)$ as it adversely affect human health. Report suggest that the use of composite nonwoven materials with membrane/coating, and nonwoven layered fabrics with finer denier fibres or even nano fibres at the upstream side of fabric are useful for controlling finer particles (Mukhopadhyay, 2009). Besides research orientation towards achieving very high efficiency for small particulates, there are extensive efforts for improving the performance of filter bag in terms of reduced energy requirement, longer bag life etc. In this regard, filter media with elaborate surface treatments by finishing/laminating/coating of fabric is often seriously considered (Xavier, et al., 2014; p 62). Among the various surface treatments, PTFE (poly tetrafluoroethylene) membrane laminated over fiberglass, polyester, and nomex to produce felt and woven filters is widely used to achieve high filtration efficiency. PTFE is well known for its chemical resistance, thermal stability, hydrophobicity and can withstand 
high temperature upto $200-220^{\circ} \mathrm{C}$. Because of the non-reactivity and non-polarity of PTFE, it is difficult for anything to bond to it. In a study (Yunlou et al., 2015; p 81), it was found that PTFE membrane coated filter media exhibit high cleaning performance. It is also reported (Mohurle \& Thakare, 2013; p. 603), that the use of PTFE membrane leads to very good emission reduction, low pressure drops, increased bag life and higher air-to-cloth ratios in metal industries, chemical industries, food industries, and coal-fired boilers.

In a recent study on filter media with silicon finish (Mukhopadhyay \& Swain, 2015; p. 40), it was found that emission was drastically reduced and the distribution of emitted particles was found to be narrow as compared to without finish filter media. Xavier et al. (2014) investigated the performance of two filter media one is of polyester nonwoven with an anti-clogging thermo-bonded surface and second was composed of acrylic polymer micropores coating over polyester needle felt. It may be added that in many cases, coating is preferred over membrane mainly for achieving durability. However, coating process must be regulated properly for achieving requisite air permeability. It can be noted that the use of PTFE coating is relatively new and is also being reported; however, study as regard its performance, has not been reported till date. In the present study, emission of fine particles and ageing behavior of PTFE finished filter media has been studied. Detail study as regard particle size distribution in the emission is quite useful information for engineering the filter media. Presence of finer particles in the upstream also determine pressure differential across the fabric; which is an important parameter affecting the energy requirement during filtration process. The behavioral pattern of pressure differential also reflects the long term performance (ageing) of the media. All these quality parameters could also be influenced by input dust density as presence of fine particles is higher at higher dust density.

Experimental results indicate that dust concentration has a small influence on filter cake density and specific resistance at constant filtration velocity, besides the obvious and proportional filtration time reduction with increasing dust concentration (in the case of cleaning on the basis of fixed pressure) (Saleem \& Krammer, 2007; p. 677). Cake density is also affected by dust concentration, whereby a denser cake evolves at low dust concentration. In another study (Mukhopadhyay \& Choudhary, 2012; p. 237), it has been found that an increase in feed dust concentration has more influence on peak pressure, but less on residual pressure drop in comparison to pulse pressure. The pressure drop is a key factor for the design and operation of the filter system. In the present research work, the effect of PTFE finish coupled with the effect of different dust concentration is also accomplished to adjudge the response of the media during filtration.

\section{Materials and Methods}

Two types of filter media (i.e., polyester with PTFE finish treatment and normal polyester needle felt) of similar mass per unit area $\left(500 \mathrm{~g} / \mathrm{m}^{2}\right)$ were taken for the present study. The material has been tested in flat form in lab equipment based on pulse jet filtration (Figure 1). Feeding of dust at predetermined constant rate can be accomplished by a dust feeder. During filtration, dust layer is formed on the fabric and it is discharged intermittently from the fabric at the upstream side which falls by gravity into a hopper and is removed periodically. The emitted dust (not retained by the media) is filtered through HEPA filter. The amount of dust deposited on the HEPA filter is useful for gravimetric analysis. The downstream side is also connected with on line particle size analyzer 'Promo 2000' (light-scattering aerosol spectrometer system) for detailed analysis of emitted particles.

The operational condition considered for the experimental work is as given below:

\section{Test conditions:}

- Face velocity: $2 \mathrm{~m} / \mathrm{min}$

- Dust concentration: 50 and $150 \mathrm{~g} / \mathrm{m}^{3}$

- Pulse jet tank pressure: 2 bar

- Valve opening time: $50 \mathrm{~ms}$

- Filter Area: $900 \mathrm{~cm}^{2}$

- Cleaning pulse at $1000 \mathrm{~Pa}$ differential pressure at the media

Test dust:

Fly Ash (the particle size distribution is shown in Figure 2)

Test sequences (As per ISO 11057):

- 30 cycles, cleaning pulse at $1000 \mathrm{~Pa}$.

- Ageing 2500 cycles with a cleaning cycle at $20 \mathrm{sec}$. 
- $\quad$ Stabilizing 10 cycles, cleaning pulse at $1000 \mathrm{~Pa}$.

- Measuring for 200 pulsing cycles at $1000 \mathrm{~Pa}$ differential pressure.

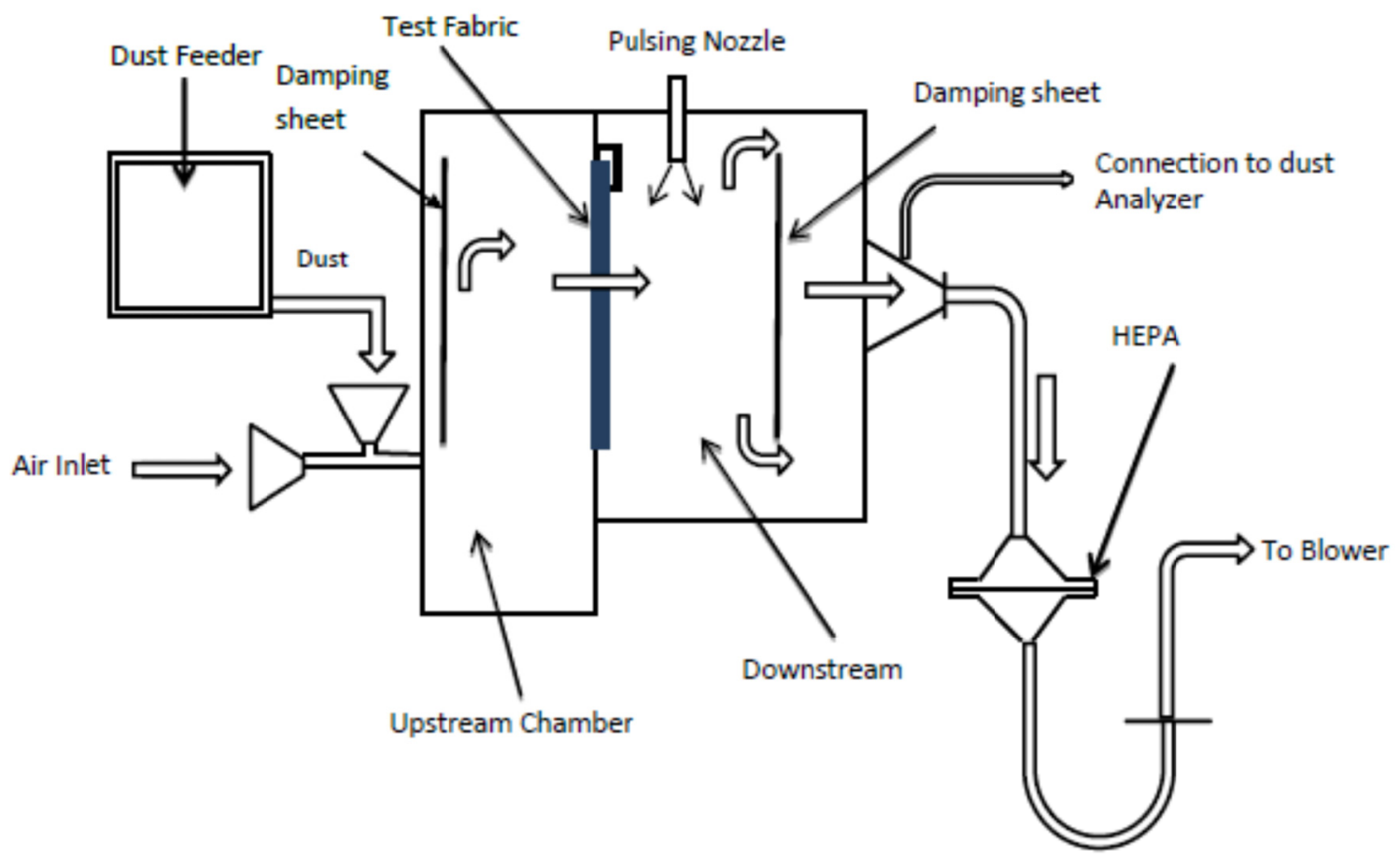

Figure 1. Experimental setup

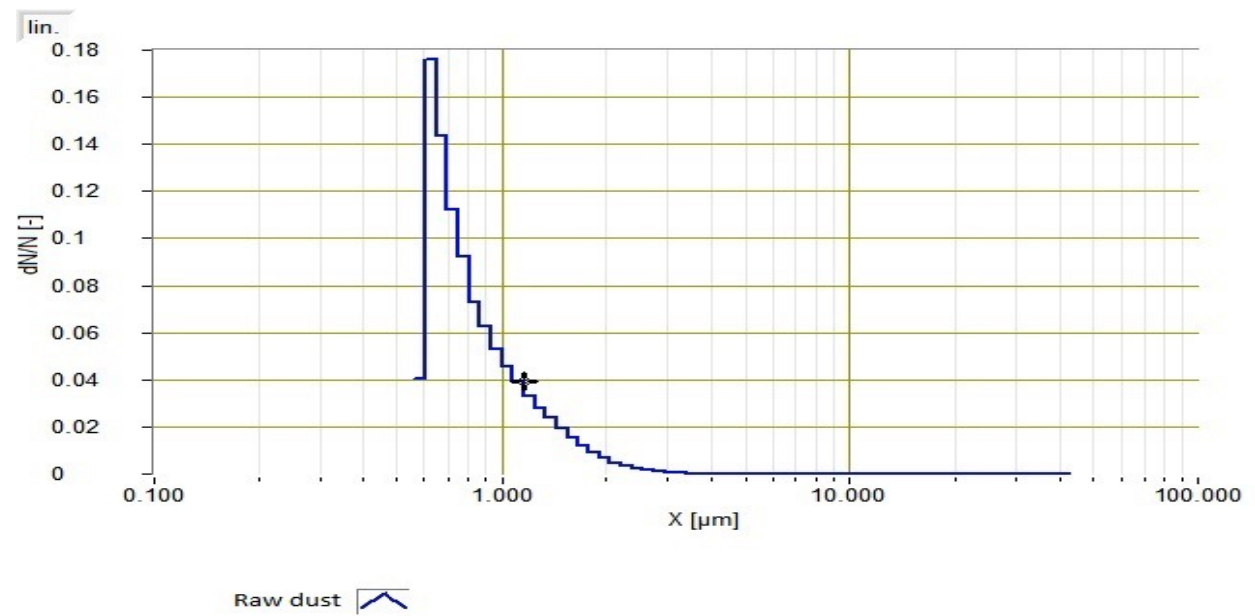

Figure 2. Raw dust distributions

The fabrics were tested based on cleaning at fixed peak pressure drop for equal number of test cycles during the first three phases (i.e. conditioning, ageing and stabilizing phase) followed by final measuring phase with 200 pulsing cycle. The factors and their levels considered for the experimental work and the experimental plan is given in Table 1 below. Results of measuring phase readings are mainly incorporated to get the real data of emission and residual differential pressure trend across the media after stabilization phase. It may be added that filtration test is quite complicated and time taking; and the test data are more relevant when the material is stabilized. Measuring phase reading was taken after passing the material through conditioning, ageing and stabilizing. However, efficiency calculation is made considering full test (all phases are included) based on gravimetric method. 
Table 1. Experimental design

\begin{tabular}{ccccccc}
\hline $\begin{array}{c}\text { Cleaning } \\
\text { Method }\end{array}$ & Run & Fabric Type & $\begin{array}{c}\text { Dust conc. } \\
\left(\mathrm{gm} / \mathrm{m}^{3}\right)\end{array}$ & $\begin{array}{c}\text { Face velocity } \\
(\mathrm{m} / \mathrm{min})\end{array}$ & $\begin{array}{c}\text { Pulse pressure } \\
(\text { Bar })\end{array}$ & Replica \\
\hline & 1 & $\begin{array}{c}\text { PTFE finish } \\
\text { Without finish }\end{array}$ & 50 & 2.0 & 2 & 2 \\
$\begin{array}{c}\text { Pressure } \\
\text { Based }\end{array}$ & 2 & 50 & 2.0 & 2 & 2 \\
$(1000 \mathrm{~Pa})$ & 3 & PTFE finish & 150 & 2.0 & 2 & 2 \\
\hline
\end{tabular}

\section{Results and Discussion}

\section{1 $P M_{2.5}$ and $P M_{10}$}

Filter media with PTFE finish and without any finish were tested in pulse jet test rig and exposed for different dust concentration viz. $50 \mathrm{gm} / \mathrm{m}^{3}$ and $150 \mathrm{gm} / \mathrm{m}^{3}$. Figure 3 shows the emission of $\mathrm{PM}_{2.5}$ and $\mathrm{PM}_{10}$. At lower dust concentration $\left(\right.$ at $50 \mathrm{gm} / \mathrm{m}^{3}$ ), absolute number of very fine particles present will be less at upstream chamber and at higher dust concentration (at $150 \mathrm{gm} / \mathrm{m}^{3}$ ), such dust particles will be expected to be 3 times higher. It may be added that emission of particle mainly take place at the time of cleaning of media when high pressure purge air acted upon the fabric for its regeneration. During pulsing pore get enlarged for very short time, in such case direct penetration becomes prominent besides seepage of particles through filter media (Mukhopadhyay, 2009). Higher the number of small particles in the upstream, penetration of particles by direct penetration and seepage is expected to be higher leading to higher emission at downstream. The application of PTFE finish enhances the surface property of filter in terms of number of pores and pore size. Modified surface structure of PTFE finished filter offer great resistance to emission as compared to without finish filter fabric. Both $\mathrm{PM}_{2.5}$ and $\mathrm{PM}_{10}$ are lower for PTFE finished fabric. The difference in the aforementioned indexes is large for unfinished fabrics; which indicate large portion of dust emission between $2.5-10 \mu \mathrm{m}$. It is further observed from Table 2 and 3 that finish type has major contribution followed by dust concentration both in the case of $\mathrm{PM}_{2.5}$ and $\mathrm{PM}_{10}$. However, the effect of dust concentration is more for $\mathrm{PM}_{2.5}$; which can be attributed due to predominate level of fine particles present in the upstream side at higher dust concentration leading to higher emission.

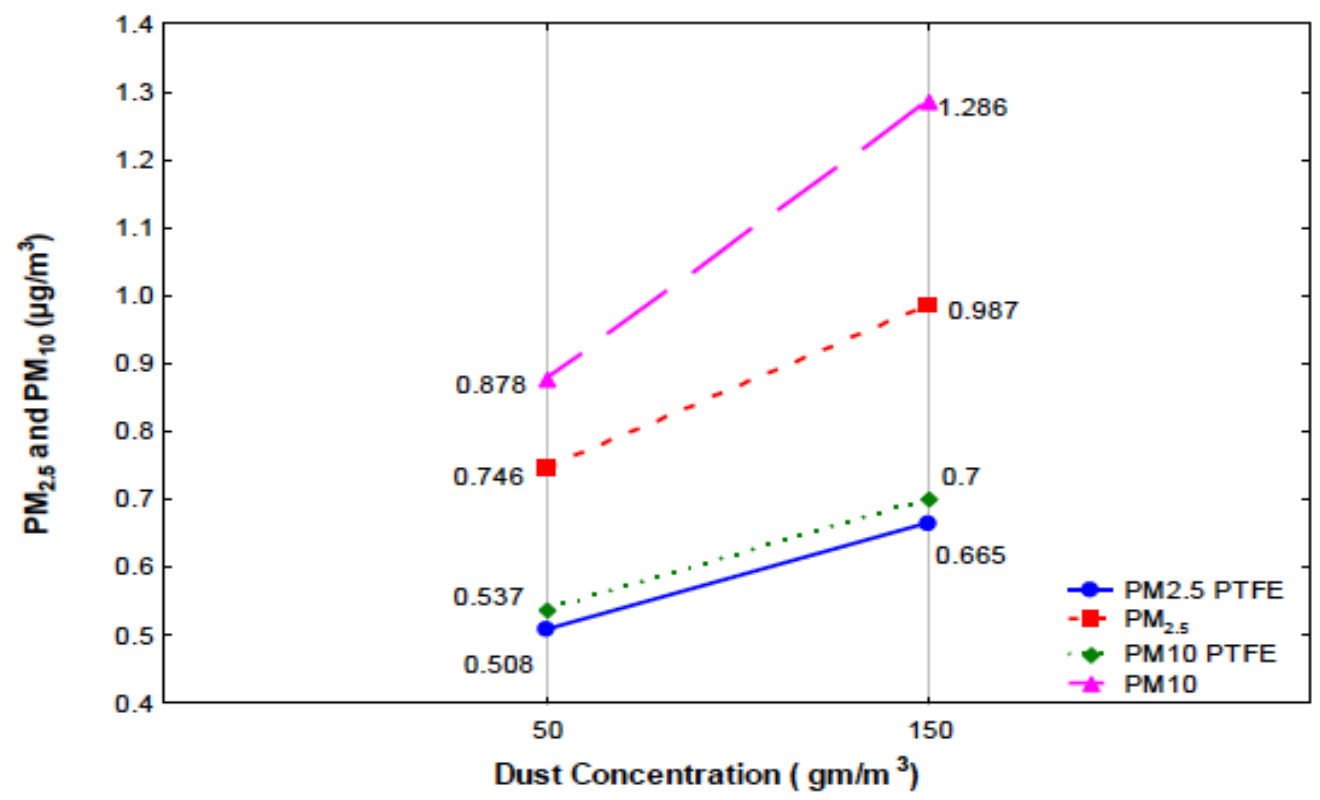

Figure 3. Effect of dust concentration and finish type on $\mathrm{PM}_{2.5}$ and $\mathrm{PM}_{10}$ 
Table 2. Analysis of Variance for $\mathrm{PM}_{2.5}$ Emissions

\begin{tabular}{llllll}
\hline Source & SS & df & MS & F & $\%$ C \\
\hline Dust Concentration & 0.079272 & 1 & 0.079272 & 316.3 & 32.48 \\
Finish type & 0.157399 & 1 & 0.157399 & 628.04 & 64.87 \\
DC x FT & 0.003553 & 1 & 0.003553 & 14.18 & 1.09 \\
Error & 0.001002 & 4 & 0.000251 & & \\
Total & 0.241227 & 7 & & & \\
\hline
\end{tabular}

Table 3. Analysis of Variance for $\mathrm{PM}_{10}$ Emissions

\begin{tabular}{llllll}
\hline Source & SS & df & MS & F & $\%$ C \\
\hline Dust Concentration & 0.160018 & 1 & 0.160018 & 624.12 & 25.99 \\
Finish type & 0.424682 & 1 & 0.424682 & 1656.38 & 69.05 \\
DC x FT & 0.028906 & 1 & 0.028906 & 112.74 & 0 \\
Error & 0.001026 & 4 & 0.000256 & & \\
Total & 0.614631 & 7 & & & \\
\hline
\end{tabular}

\subsection{Particle Concentration in the Emission}

It is observed that particle concentration in clean air increases with the increase in feed dust concentration (Figure 4). PTFE finished fabric shows lower number of particle emission than without finished fabric in both dust concentration. At lower dust concentration, PTFE finished fabric shows 5\% lower number of particles than non-finished fabric; whereas at high dust concentration it shows $37 \%$ lower emission. The result indicates that PTFE finished fabric is more beneficial at higher dust concentration. ANOVA results as in Table 4 also indicate high level of interaction among dust concentration finish type. It may be noted that the difference in emitted dust mass concentration $\left(\mathrm{PM}_{2.5}\right.$ and $\left.\mathrm{PM}_{10}\right)$ is lower in case of finished and unfinished filter compared to its effect on number concentration of emitted particles. This can be attributed to increase in number of very fine particles in emission which cause much less changes in mass of particles. Figure $5-6$ represent data of particle size distribution both at measuring phase and entire test while working with two different level of feed dust concentration. It has been observe that PTFE finished fabric is particularly more effective for capturing very fine particles as compared to without finished fabric. This is valid both in the measuring phase and during entire test phase. 


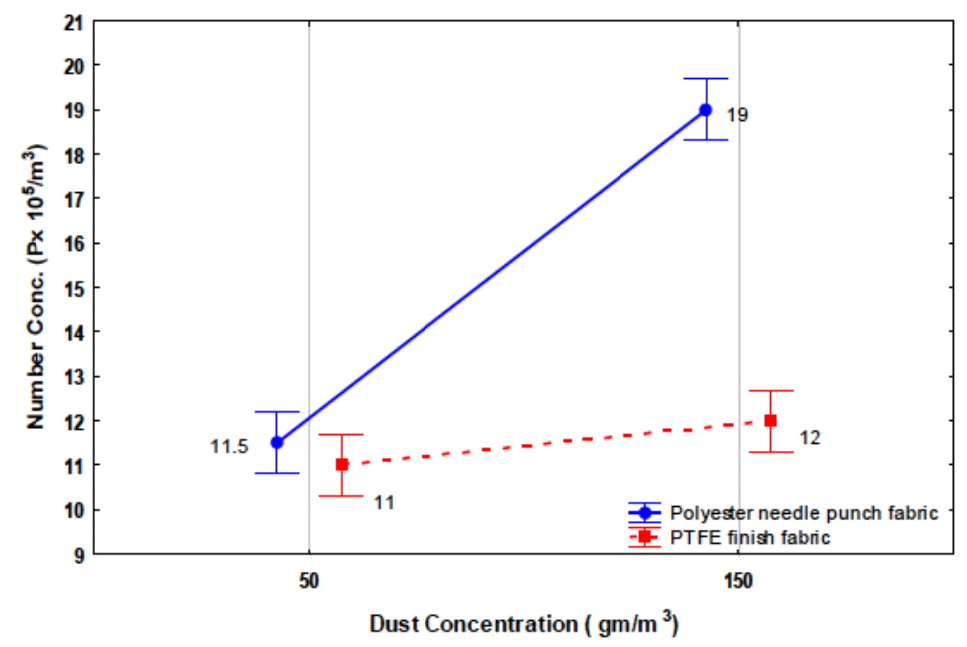

Figure 4. Effect of dust concentration and finish type on particle concentration

Table 4. Analysis of variance for particle concentration

\begin{tabular}{llllll}
\hline Source & SS & df & MS & F & \%C \\
\hline Dust Concentration & 36.125 & 1 & 36.125 & 289 & 41.92 \\
Finish type & 28.125 & 1 & 28.125 & 225 & 32.60 \\
DC x FT & 21.125 & 1 & 21.125 & 169 & 24.45 \\
Error & 0.500 & 4 & 0.125 & & \\
Total & 85.87500 & 7 & & & \\
\hline
\end{tabular}

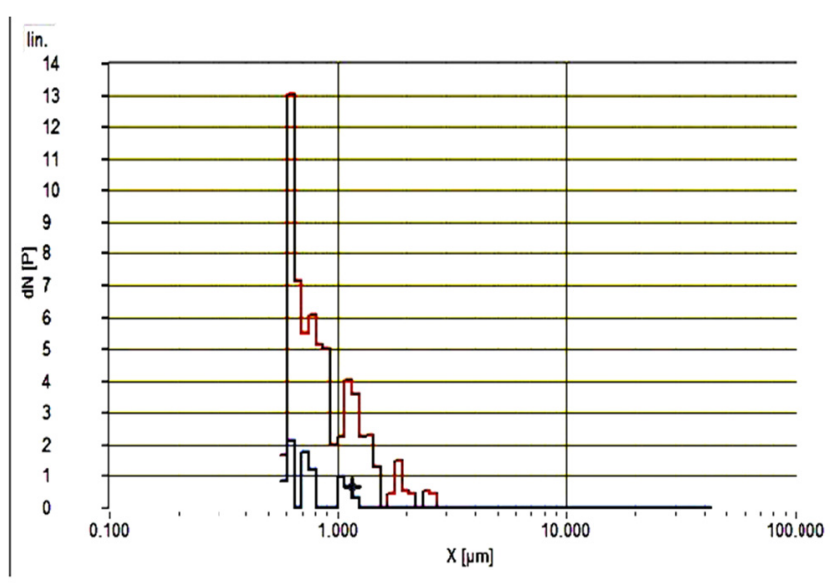

Polyester needle punch fabric

PIFE finish fabric

(a)

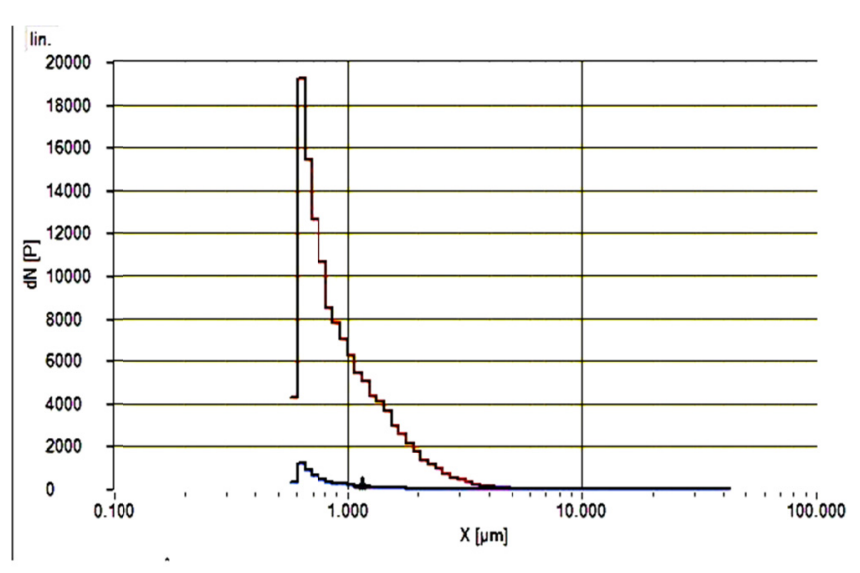

Polyester needle punch fabric $\longdiv { \widehat { N } } \quad$ PTFE finish fabric $\longdiv { \widehat { \nearrow } }$

(b)

Figure 5. Emitted particles size distribution at $50 \mathrm{gm} / \mathrm{m}^{3}$ inlet dust concentration (a) measuring phase (b) full test phase 


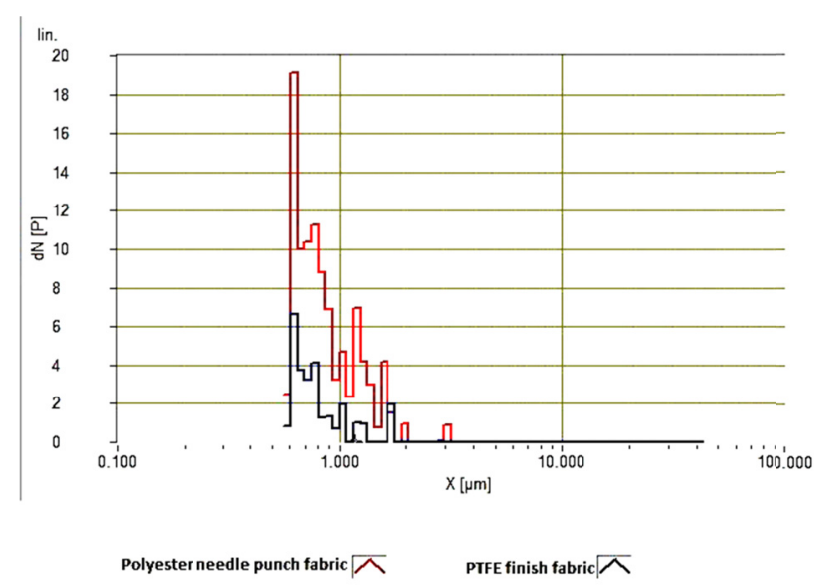

(a)

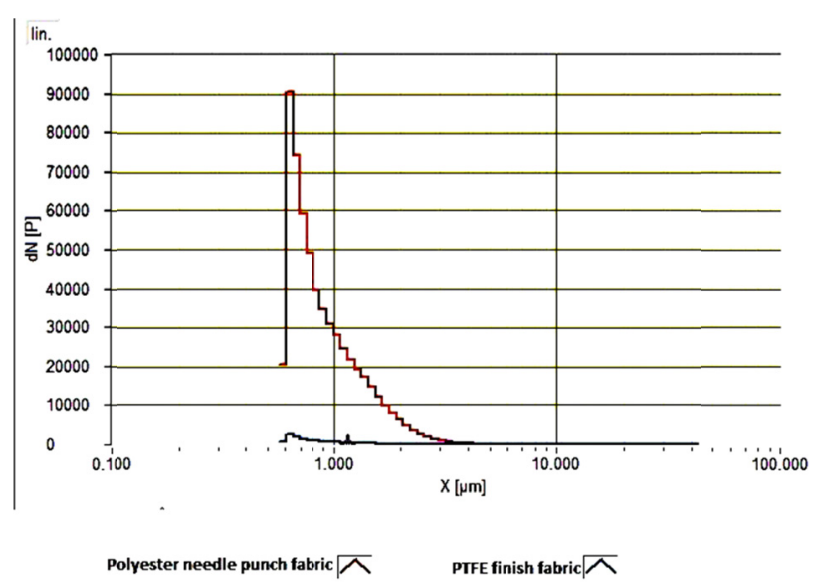

(b)

Figure 6. Emitted particles size distribution at $150 \mathrm{gm} / \mathrm{m}^{3}$ inlet dust concentration (a) measuring phase (b) full test phase

\subsection{Residual Pressure Difference}

It is observed that at higher dust concentration, there is increase in residual pressure drop (Figure 7). This is expected as at higher dust concentration more number of particles tends to clog the pores of the material, leading to higher average differential pressure. The property of PTFE finished material is to easy dislodge dust cake while pulsing (due to less adhesion tendency of material); which results in lower level of the primary cake layer (which take part in filtration) over PTFE treated fabric. Further tendency of clogging of pores substantially reduce for PTFE treated fabric. All these effects leads to lower differential pressure across PTFE treated fabric. It has also been observed that dust concentration accounts for highest contribution (63\%) to residual pressure followed by the effect of finish (Table 5). This indicates clogging of pores due to the presence of finer particles at higher dust concentration plays a vital role in influencing pressure differential across the fabric.

Figures 8 and 9 also indicate that in spite of additional surface treatment, PTFE finished fabric exhibits less residual pressure at both the dust concentration. Trend for polyester filter fabric can be expressed as

Residual pressure drop $\quad=563.6308-0.3694 \mathrm{x}+0.0014 \mathrm{x}^{2} \ldots$ at $50 \mathrm{gm} / \mathrm{m}^{3}$ dust concentration (PTFE finished fabric)

Residual pressure drop (Without $=686.0627+0.4479 \mathrm{x}+0.0034 \mathrm{x}^{2} \ldots$. at $50 \mathrm{gm} / \mathrm{m}^{3}$ finish)

Residual pressure drop (PTFE $\quad=771.0689-0.4977 \mathrm{x}+0.001 \mathrm{x}^{2} \ldots \ldots .$. at $150 \mathrm{gm} / \mathrm{m}^{3}$ dust concentration finished fabric)

Residual pressure drop (Without $=804.855+0.5056 \mathrm{x}-0.0011 \mathrm{x}^{2} \ldots \ldots$... $150 \mathrm{gm} / \mathrm{m}^{3}$ dust concentration finish) 


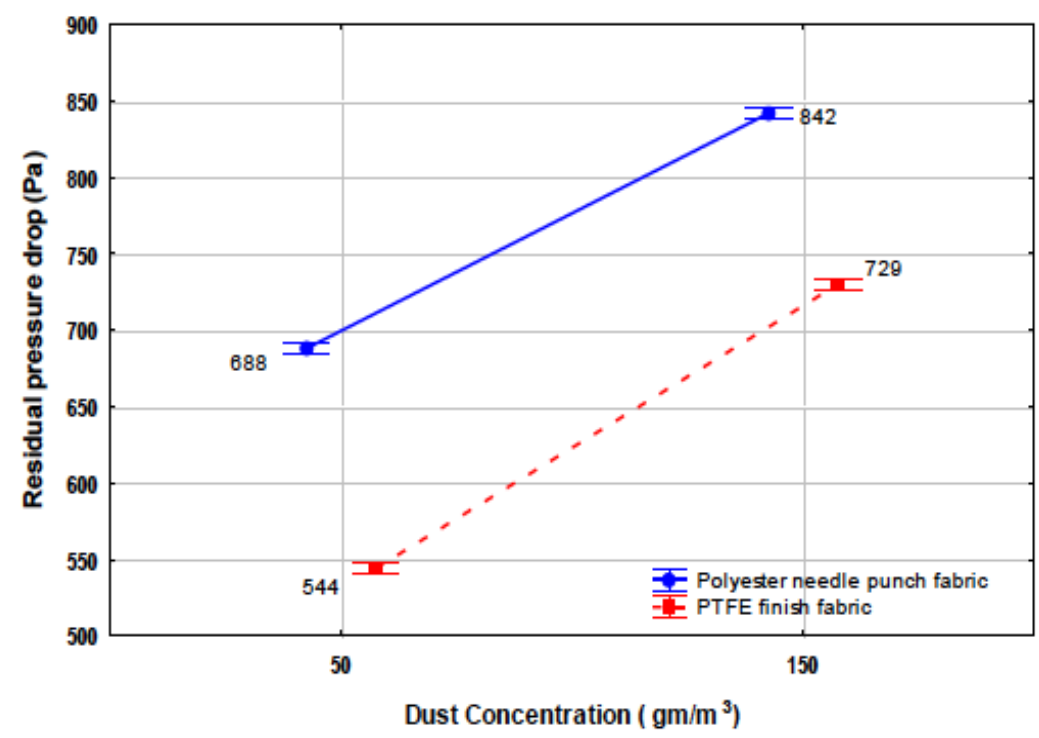

Figure 7. Average residual pressure

Table 5. Analysis of variance for residual pressure

\begin{tabular}{llllll}
\hline Source & SS & df & MS & F & \%C \\
\hline Dust Concentration & 57427 & 1 & 57427 & 14897 & 63.29 \\
Finish type & 32794 & 1 & 32794 & 8507 & 36.14 \\
DC x FT & 484 & 1 & 484 & 125 & 0.5 \\
Error & 15 & 4 & 4 & & \\
Total & 90719 & 7 & & & \\
\hline
\end{tabular}

Equations show that in case of regular polyester needle punched fabric, the pulsing cycles needed to reach 1000 Pa are 1184 and 706 for $50 \mathrm{gm} / \mathrm{m}^{3}$ and $150 \mathrm{gm} / \mathrm{m}^{3}$ dust concentration respectively (derived through equation). On the other hand, it is not possible to find the cycles at which residual pressure drop will reach to $1000 \mathrm{~Pa}$ in the case of PTFE finished media. These are only indicative as regard life of filter media. It indicates that PTFE filter can offer longer life as it shows stable pressure differential without any rising trend with time as in the case of normal polyester filter media. 


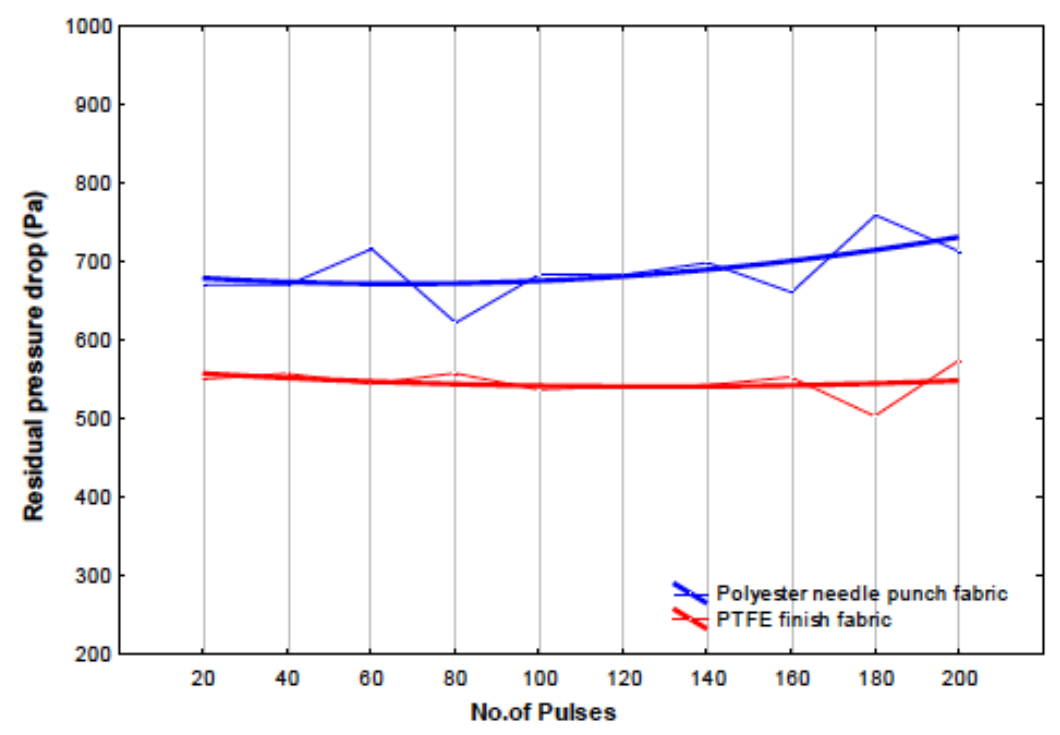

Figure 8 . Residual pressures at $50 \mathrm{gm} / \mathrm{m}^{3}$ dust concentration

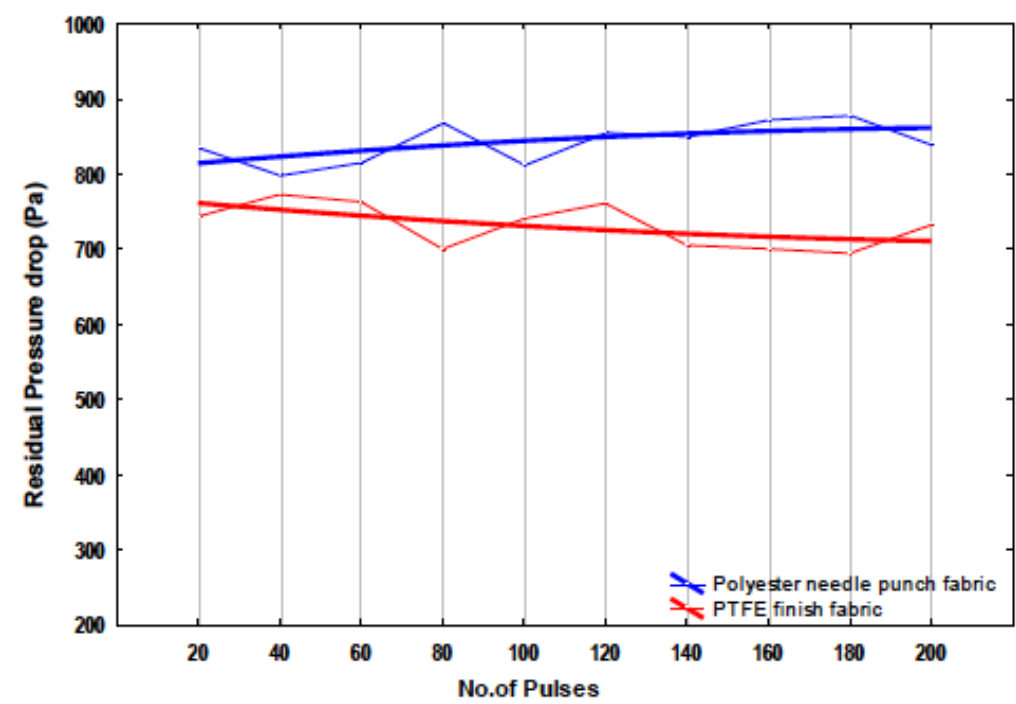

Figure 9. Residual pressures at $150 \mathrm{gm} / \mathrm{m}^{3}$ dust concentration

\subsection{Ageing Characteristics}

Assessment of ageing characteristics can be done by addition of time for first conditioning, ageing and stabilizing phases. Lesser the time period for the above phases indicates earlier stabilization of the media; which in turn leads consistent filtration efficiency and better long term performance of the media. Figure 10 shows that PTFE finished fabric possess better ageing characteristics than non-finish fabric in both dust challenges. At higher dust concentration ageing take place earlier; however, its effect is negligible as compared to the effect finish (from ANOVA Table 6). 


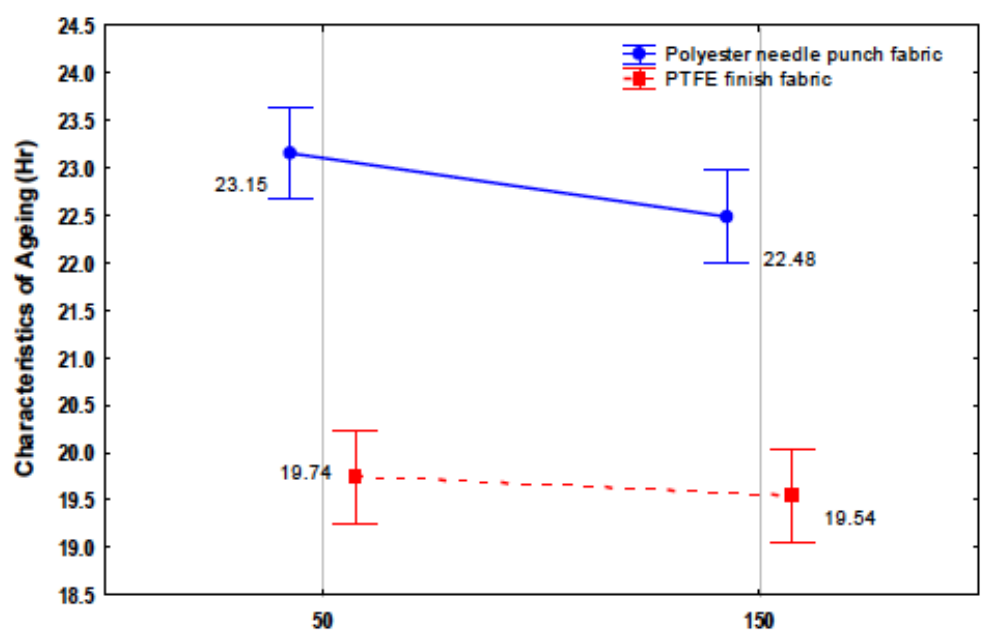

Figure 10. Effect of dust concentration and finish type on ageing characteristics

Table 6. Analysis of Variance for ageing characteristics

\begin{tabular}{llllll}
\hline Source & SS & df & MS & F & $\%$ C \\
\hline Dust Concentration & 0.383 & 1 & 0.383 & 6.25 & 1.24 \\
Finish type & 20.193 & 1 & 20.193 & 329.75 & 95.89 \\
DC x FT & 0.108 & 1 & 0.108 & 1.77 & 0 \\
Error & 0.245 & 4 & 0.061 & & \\
Total & 20.929 & 7 & & & \\
\hline
\end{tabular}

\section{Conclusions}

Present study involves study of newly developed PTFE finished filter media during pulse jet filtration at two levels of dust concentration. The study is mainly encompasses performance of PTFE finished filter media towards emission of fine particles, pressure differential and ageing behavior. Emission in terms of mass concentration $\left(\mathrm{PM}_{2.5}, \mathrm{PM}_{10}\right)$ and number particle concentration are substantially lower while using PTFE finished polyester fabric as filter media in comparison to without finish polyester fabric. Outgoing particle number largely reduced for PTFE treated fabrics particularly while working at higher dust concentration. However, the magnitude of improvement is relatively small in terms of $\mathrm{PM}_{2.5}$ and $\mathrm{PM}_{10}$. This has been attributed to the fact that emission of large amount of very fine particles cause less increment in mass at the downstream. Presence of absolute number of fine particles is inevitably very useful indicator in case of environmental pollution. The particle size distribution in the downstream side reflects that use PTFE finished filter is particularly more beneficial for capturing very fine particle.

PTFE finished fabric exhibit lower residual pressure drop as compared to unfinished fabric during measuring phase of filtration operation. The aforesaid finding indicates that in addition to other benefits of PTFE treated fabrics, energy requirement will be also less. Further it is also evident that the trend of residual pressure drop with time is quite stable for PTFE finished fabrics. The trends also indicate that life of PTFE treated fabric will be longer than without treated fabrics. PTFE finished fabric get stable (age) earlier than without finished fabric, hence provide more consistent filtration for longer time.

\section{References}

Mohurle, N., \& Thakare, N. (2013). Analysis on Fabric Filtration Material for Pulse Jet Fabric. International Journal of Emerging Technology and Advanced Engineering Filter, 3(6). 603-609. 
Mukhopadhyay, A. (2009). Pulse-jet filtration: An effective way to control industrial pollution Part I: Theory, selection and design of pulse-jet filter. Textile Progress (monograph), Taylor \& Francis, UK, 41(4). http://dx.doi.org/10.1080/00405160903437948

Mukhopadhyay, A. (2010). Pulse-Jet Filtration: An Effective Way to Control Industrial Pollution; Part II: Process Characterization and Evaluation of Filter Media, Textile Progress (monograph), Taylor \& Francis, UK, 42(1).

Mukhopadhyay, A., \& Choudhary, A. K. (2012). Analysis of dust deposition on industrial surface filter as a function of its physical properties. Filtration Journal, American Filtration Society, USA, 12(4). 237 -246.

Mukhopadhyay, A., \& Swain, S. R. (2015). Effect of Silicon Finish on the behaviour of Regenerated Surface Filters at Different Dust Concentration. Filtration Journal, American Filtration Society, USA, 15(1). 40-47.

Saleem, M., \& Krammer, G. (2007). Effect of filtration velocity and dust concentration on cake formation and filter operation in a pilot scale jet pulsed bag filter. J. Hazardous Materials, 144, 677-681. http://dx.doi.org/10.1016/j.jhazmat.2007.01.094

Xavier, S., Dennis, B., Sandrine, C., \& Dominique, T. (2014). Downstream particle puffs emitted during pulse-jet cleaning of a baghouse wood dust collector: Influence of operating conditions and filter surface treatment. Powder Technology, 261, 61-70. http://dx.doi.org/10.1016/j.powtec.2014.04.028

Yang, C. (2012). Aerosol Filtration Application Using Fibrous Media-An Industrial Perspective. Chinese Journal of Chemical Engineering, 20(1), 1-9. http://dx.doi.org/10.1016/s1004-9541(12)60356-5

Yunlou, Q., Yuanxia, B., Mingxing, Haiyan, Z. C., \& Guanjie, X. (2015). Effect of filtration operation and surface treatment on pulse-jet cleaning performance of filter bags. Powder Technology, 277, 82-88. http://dx.doi.org/10.1016/j.powtec.2015.02.036

\section{Copyrights}

Copyright for this article is retained by the author(s), with first publication rights granted to the journal.

This is an open-access article distributed under the terms and conditions of the Creative Commons Attribution license (http://creativecommons.org/licenses/by/3.0/). 